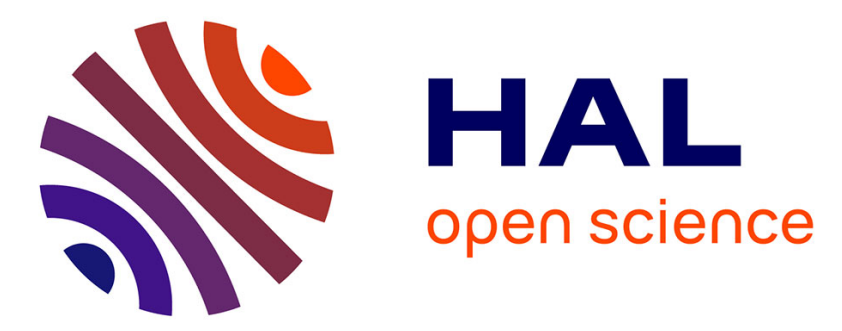

\title{
MEASUREMENT OF FUNDAMENTAL AND SECOND HARMONIC PRESSURES IN THE FIELD OF A CIRCULAR PISTON SOURCE
}

\author{
Mark Moffett
}

\section{- To cite this version:}

Mark Moffett. MEASUREMENT OF FUNDAMENTAL AND SECOND HARMONIC PRESSURES IN THE FIELD OF A CIRCULAR PISTON SOURCE. Journal de Physique Colloques, 1979, 40 (C8), pp.C8-39-C8-43. 10.1051/jphyscol:1979808 . jpa-00219513

\section{HAL Id: jpa-00219513 https://hal.science/jpa-00219513}

Submitted on 1 Jan 1979

HAL is a multi-disciplinary open access archive for the deposit and dissemination of scientific research documents, whether they are published or not. The documents may come from teaching and research institutions in France or abroad, or from public or private research centers.
L'archive ouverte pluridisciplinaire HAL, est destinée au dépôt et à la diffusion de documents scientifiques de niveau recherche, publiés ou non, émanant des établissements d'enseignement et de recherche français ou étrangers, des laboratoires publics ou privés. 


\title{
MEASUREMENT OF FUNDAMENTAL AND SECOND HARMONIC PRESSURES IN THE FIELD OF A CIRCULAR PISTON SOURCE
}

\author{
Mark B. Moffett
}

Naval Underwater Systems Center, New London Laboratory, New London, Connecticut 06320, USA.

Résumé.- La composante fondamentale et le second harmonique d'une onde acoustique d'amplitude finie produite par un projecteur de $10,2 \mathrm{~cm}$ de diamètre à la fréquence de $450 \mathrm{kHz}$ ont été mesurês à différentes distances, entre $1 \mathrm{~m}$ et $131 \mathrm{~m}$, dans 1 'eau pure. Différents niveaux furent utilisés de façon à obtenir des régimes saturés et non-saturés du champ sonore. Les niveaux non-saturés mesurés en champ proche sont en bon accord avec la thêorie de Ingenito et Williams (J.A.S.A. 49 (1971) 319-328), tandis que les niveaux non-saturés mesurés en champ lointain correspondent à la thêrie de Safar (J. Sound Vib. 13 (1970) 1-7). Le second harmonique étant généré localement ã des distances de l'ordre de $1 / \alpha(\alpha=\bar{c}$ coefficient d'absorption du fondamental), la théorie de Safar peut être modifiée de façon à faire cadrer les niveaux saturés mesurés à ces distances en appliquant au fondamental les pertes par amplitude finie. Le diagramme de directivitë du second harmonique, à ces distances, est trēs voisin du carré du diagramme de directivité mesuré pour le fondamental.

Abstract.- Measurements were made at various ranges between $1 \mathrm{~m}$ and $131 \mathrm{~m}$ of the fundamental and second harmonic components of a finite-amplitude sound wave produced by a 10.2-cm-diameter projector driven at $450 \mathrm{kHz}$ in fresh water. Various levels were used, so that nonsaturated, as well as saturated, conditions obtained. The nonsaturated, nearfield levels are in good agreement with the theory of Ingenito and Williams (J.Acoust.Soc.Am. 49 (1971) 319-328), while the nonsaturated, farfield levels agree with the theory of Safar (J. Sound Vib. 13 (1970) 1-7). Because the second harmonic component becomes locally generated at ranges of the order of $1 / \alpha$ ( $\alpha=$ fundamental absorption coefficient), the Safar theory can be modified to fit the saturated levels at such ranges by correction of the fundamental levels for finite-amplitude losses. The second harmonic beam patterns at such ranges closely approximate the square of the measured fundamental beam patterns.

1. Introduction.- One of the consequences of medium nonlinearity is the generation of harmonic frequencies during the propagation of an initially-sinusoidal sound wave. Although this problem has been treated thoroughly for plane waves /1-4/, and approximately for spherical waves $/ 5-7 /$, it is only recent ly that any progress has been made in predicting the harmonic levels from directional projectors /8-11/. Ingenito and Williams /8/ and Rogers /9/ have examined the absorption-free circular piston nearfield Lockwood, Muir and Blackstock /10/ and Ostrovskii and Fridman /11/ treated directional spherical waves (i,e., the farfield of a directional source). More recently, Fenlon /12/ has developed a combined plane- and spherical-wave Burgers Equation. His solution ignores the harmonic levels at long range, however.

Measurements of the second harmonic content have been made for spherical wave fields $/ 13 /$ and for the fields of circular piston-like sources $/ 10 /$, /14-21/. Nearfield measurements have been made optically /14/ and acoustically with large, planar receivers /15-17/ and with probe hydrophones /18-19/. Farfield data have been obtained acoustically in air $/ 20 / / 21 /$ and in water $/ 10 /$. However, one of the remaining questions requiring an experimental answer concerns the absorption rate of the second harmonic in the old-age region (i.e., ranges greater than $1 / \alpha$, where absorption of the harmonics re-esta blishes the sinusoidal waveshape). Although theory indicates that the ultimate, long-range absorption rate should be twice that of the fundamental component i.e., $2 \alpha$, the date of Lockwood, Muir and $B$ lackstock /10/ suggested a rate equal to $4 \alpha$. The present experiment was undertaken to resolve this discrepancy by measuring second harmonic levels out to ranges on the order of $1 / \alpha$.

2. Theory.- Since there exists no comprehensive theory, able to deal simultaneously with absorption and finite-amplitude distortion in both the nearfield and farfield of the circular piston, we resort to a "piecewise" theoretical approach. For the nearfield at low levels (i.e., prior to saturation), the theory of Ingenito and Williams /8/ is appropriate. For the farfield at low levels, we use the spherical-wave result of Safar /6/ :

$p_{2} / p_{0}=\left(\sigma_{0} R_{0} / 2 r\right) \exp (-4 a r) I_{3}$,

where :

$\sigma_{0} \equiv B \omega P_{0} R_{0} / \rho C^{3}$ 
$I_{3} \equiv \int_{1}^{r / R_{0}} \exp \left(2 \alpha R_{0} y\right) y^{-1} d y=E i(2 \alpha r)-E i\left(2 \alpha R_{0}\right)$.

In these expressions, $P_{0}$ is the average face pressure amplitude, $r$ the range, $R_{0}$ the Rayleigh length (= projector area/fundamental wavelength), w the fundamental angular frequency, $\rho$ the density, $C$ the sound speed, $\alpha$ the fundamental absorption coefficient (Nepers per unit length) and $\beta$ a nonlinearity parameter ( $\simeq 3.5$ in water). The parameter $\sigma_{0}$ is the ratio of $R_{0}$ to the shock-formation distance of a plane wave whose amplitude is $P_{0}$. Thus, $\sigma_{0}$ is a measure of the amount of distortion occurring within the nearfield.

In order to describe the second harmonic at high levels in the old-age region, we assume that the second harmonic is locally generated $/ 22 /$, i.e., generation occurring at distances greater than $1 / \alpha$ from the observation point may be ignored. One may then employ a perturbation theory $/ 23$ / to calculate the second harmonic generated by the local value of the fundamental component. In the old-age region this local value will be :

$S P L_{1}=S L_{0}-20 \log r-\bar{\alpha} r-E X D B$,

where EXDB is the extra loss (in $\mathrm{dB}$ ) due to finiteamplitude effects, and :

$S L_{0}=20 \log P_{0} R_{0}-3$

is the rms fundamental source level (in the absence of nonlinearity). Equation 1, which is the perturbation theory result for EXDB $=0$, may now be modified for the case of nonzero EXDB by subtracting EXOB from the fundamental "unperturbed" pressure level. In decibel form, the result for the axial second harmonic sound pressure level is :

$S P L_{2}=2\left(S L_{0}-E X D B\right)-20 \log r+20 \log f$

$$
-4 \bar{\alpha} r+20 \log I_{3}-S L_{1}^{*}-6 \text {, }
$$

where $f$ is the fundamental frequency (in $\mathrm{kHz}$ ), $\bar{\alpha}=8.686 \alpha$, and :

$\mathrm{SL}_{1}^{*} \equiv 20 \log \left(\rho \mathrm{C}^{3} / 2 \sqrt{2} \mathrm{\beta} \beta\right)+60 \mathrm{~dB} / / 1_{\mu} \mathrm{Pa}-\mathrm{m}-\mathrm{kHz} .(7)$ In fresh water $/ 24 /, \mathrm{SL}_{1}{ }^{*} \simeq 280 \mathrm{~dB} / / I_{\mu \mathrm{Pa}-\mathrm{m}-\mathrm{kHz}}$.

Although Eq. 6 contains the term - $4 \bar{\alpha} r$, the effective absorption rate at long range is $2 \bar{\alpha}$, because :

$I_{3} \underset{\alpha r \gg 1}{\longrightarrow} \exp (2 \alpha r) / 2 \alpha r$.

However, ranges in excess of $5 / \alpha$ are required for this asymptotic limit to approach the correct value within $1 \mathrm{~dB}$. Thus ärmust exceed $40 \mathrm{~dB}$ for the $2 \bar{\alpha}$ second harmonic absorption rate to hold. At shorter ranges, higher effective absorption rates may be expected.

The farfield angular dependence of the second harmonic component at low levels has been shown /10/ to have the form :

$D_{2}(\theta)=\left\{D_{0}(\theta)\right\}^{2}$,

where $D_{0}$ is the small-signal (i.e., unperturbed) fundamental beam pattern. In the old-age region, the fundamental beam pattern, $D_{1}(\theta)$ is, in general, broadened because of saturation near the axis. Invoking the local generation concept again, we modify Eq. 9 to account for the broadened "unperturbed" pattern by taking :

$D_{2}(\theta)=\left\{D_{1}(\theta)\right\}^{2}$.

3. Experiment.- The experiment was conducted in a fresh water transducer calibration facility in late winter, 1977. The pond was ice-covered and holes were cut at various ranges to allow hydrophone emplacement. The water temperature was $3.3^{\circ} \mathrm{C}$, so that $C=1418 \mathrm{~m} / \mathrm{sec}$ and $\bar{\alpha}=0.085 \mathrm{~dB} / \mathrm{m}$. The projector had a $10.2 \mathrm{~cm}$ active diameter and was operated at a fundamental frequency of $450 \mathrm{kHz}$. The Rayleigh length, $R_{0}$, was $2.58 \mathrm{~m}$. The projector was mounted on a rotatable shaft and driven with a $10-\mathrm{kW}$ pulsed power amplifier. The hydrophone was used for receiving both the fundamental and second harmonic signals, which were subsequently selected with a bandpass filter. It was determined that negligible second harmonic levels were directly radiated by the projector, by means of a close-range $(r=0.2 \mathrm{~m})$ measurement which yielded levels significantly below those at $r=1 \mathrm{~m}$.

The extra loss, EXDB, at long range was measured by noting the departure (in $\mathrm{dB}$ ) of the fundamental received signal from linearity as the projec tor voltage was increased from low levels.

4. Results and conclusions. - Three values of EXDB are tabulated in table $I$. The location of shock inception, if any, is also indicated in the table. Propagation data for the fundamental component at these three levels are plotted in figure 1. It may be seen that beyond $r=20 \mathrm{~m}$, the data follow the (solid) curves given by Eq. 4, i.e., beyond this range, the extra loss is constant and the propagation is characterized by spherical spreading and absorption. 
Table I. EXDB as a function of projector voltage, extrapolated source level, and $\sigma_{0}$.

$\begin{array}{cccccc}\begin{array}{c}\text { Projector } \\ \text { Voltage } \\ (\text { Vpk-pk) }\end{array} & \begin{array}{c}\text { Voltage } \\ \text { Level } \\ \left(\mathrm{dB} / / 1 \mathrm{~V}_{\text {rms }}\right)\end{array} & \begin{array}{c}\mathrm{SL}_{\mathrm{o}} \\ (\mathrm{dB} / / 1 \mu \mathrm{Pa}-\mathrm{m})\end{array} & \sigma_{0} & \begin{array}{c}\text { EXDB } \\ (\mathrm{dB})\end{array} & \begin{array}{c}\text { Shock } \\ \text { Formation }\end{array} \\ 75 & 28.5 & 215.0 & 0.250 & 0.5 & \text { None } \\ 250 & 39.0 & 225.5 & 0.838 & 5.5 & \text { Farfield } \\ 750 & 48.5 & 235.0 & 2.50 & 12.5 & \text { Nearfield }\end{array}$

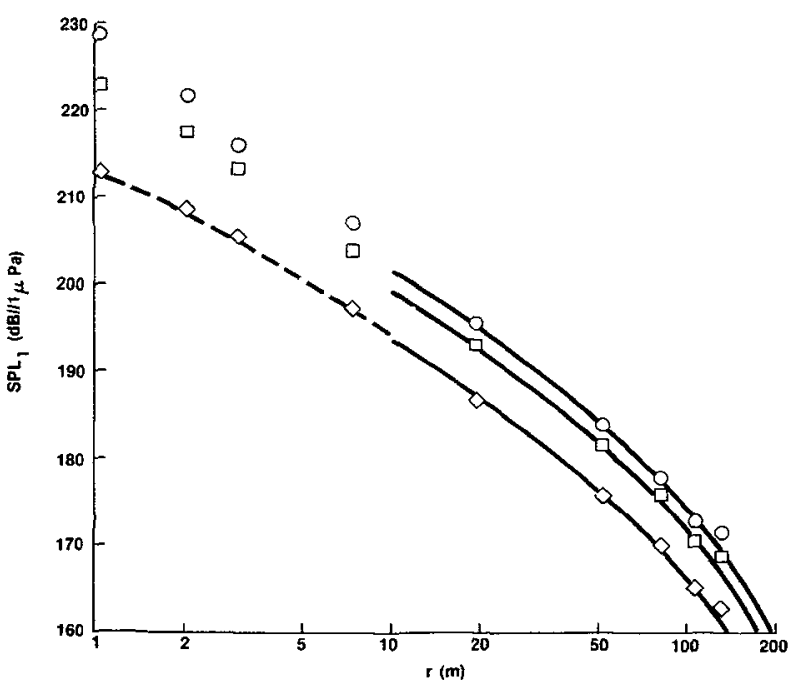

Figure 1 : Sound pressure level of fundamental component for projector voltages of $750 \mathrm{Vpp}$ (circles), $250 \mathrm{Vpp}$ (squares) and $75 \mathrm{Vpp}$ (diamonds). Solid curves : Eq. 4. Dashed curve : smal1-signal theory.

Second harmonic levels for the same three pro jector voltages are shown in figure 2. Beyond $r \simeq$ $20 \mathrm{~m}$, the data follow the predictions of Eq. 6 (solid curves), so that the Safar theory $/ 6 /$, modified by the inclusion of finite amplitude losses, provides an adequate description of the second harmonic behavior in the old-age region at all levels. At the lowest level, wherein no shocks form, the theory of Ingenito and Williams $/ 8 /$, although usually considered a nearfield theory, is satisfactory out to $r \simeq 20 \mathrm{~m}$, about $8 \times R_{0}$, in this case.

We turn now to the question of the secondharmonic absorption rate. As indicated in Section 2 we expect a $2 \bar{\alpha}$ rate to obtain when $\overline{a r}$ exceeds about $40 \mathrm{~dB}$. Unfortunately, the maximum $\bar{\alpha} r$ in this experiment was about $11 \mathrm{~dB}$, so that the ranges were not large enough for the $2 \bar{\alpha}$ rate to be observed. Rather, a rate $\simeq 3 \bar{\alpha}$ prevailed over much of the range. Figure 3 illustrates this fact by plotting the second harmonic levels corrected for spherical spreading versus range on a linear scale. The theoretical curve, $-4 \bar{a} r+20 \log I_{3}$, is shown solid in the $f i$ gure, and dashed lines of slope $-2 \bar{\alpha}$ and $-4 \bar{\alpha}$ are shown for comparison. Ultimately, at ranges $\simeq 500 \mathrm{~m}$ the $2 \bar{\alpha}$ rate should obtain. However, the total second harmonic absorption loss at $500 \mathrm{~m}$ would exceed $100 \mathrm{~dB}$, so that little practical use could be made of the second harmonic signal at that range. As a practical matter, it is perhaps better to approximate the second harmonic absorption rate by $3 \bar{\alpha}$.

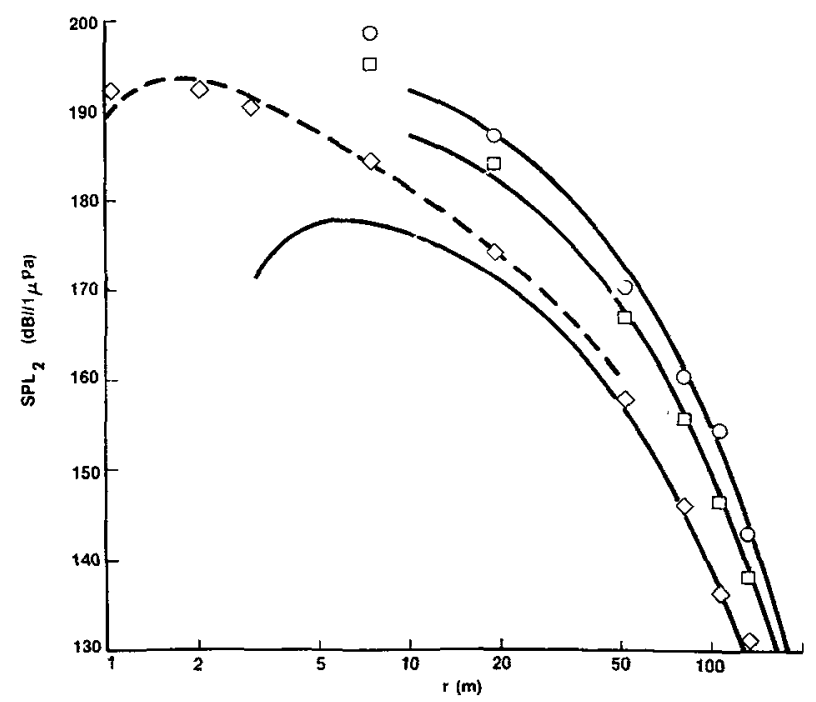

Figure 2 : Sound pressure level of second harmonic component for projector voltages of $750 \mathrm{Vpp}$ (circles) $250 \mathrm{Vpp}$ (squares) and $75 \mathrm{Vpp}$ (diamonds). Solid curves : Eq. 6. Dashed curve : theory of ref. 8.

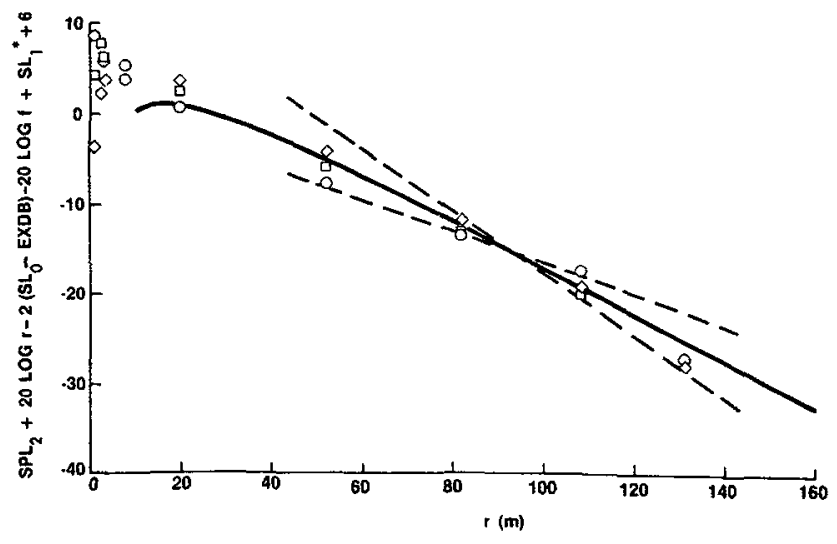

Figure 3 : Second harmonic sound pressure levels corrected for spherical spreading and input levels for projector voltages of $750 \mathrm{Vpp}$ (circles), 250Vpp (squares) and $75 \mathrm{Vpp}$ (diamonds). Solid curve : $4 \bar{\alpha} r+20 \log \mathrm{I}_{3}$. Dashed lines have slopes of $2 \bar{\alpha}$ and $4 \bar{\alpha}$. 
The second harmonic beam pattern data measured at $52.2 \mathrm{~m}$ are plotted as symbols in figure 4 . Again, the data are for three projector voltages, viz., $80 \mathrm{Vpp}, 250 \mathrm{Vpp}$ and $750 \mathrm{Vpp}$. The solid curves are the squared fundamental beam patterns for the same applied voltages. These exhibit broadening and increased sidelobe levels as the level is raised. It may be seen that Eq. 10 is experimentally verified. Thus the result of Lockwood, Muir and Blackstock $/ 10 /$, although originally intended for nonsaturated waves, can be extended to saturated cases by use of the actual fundamental beam pattern.

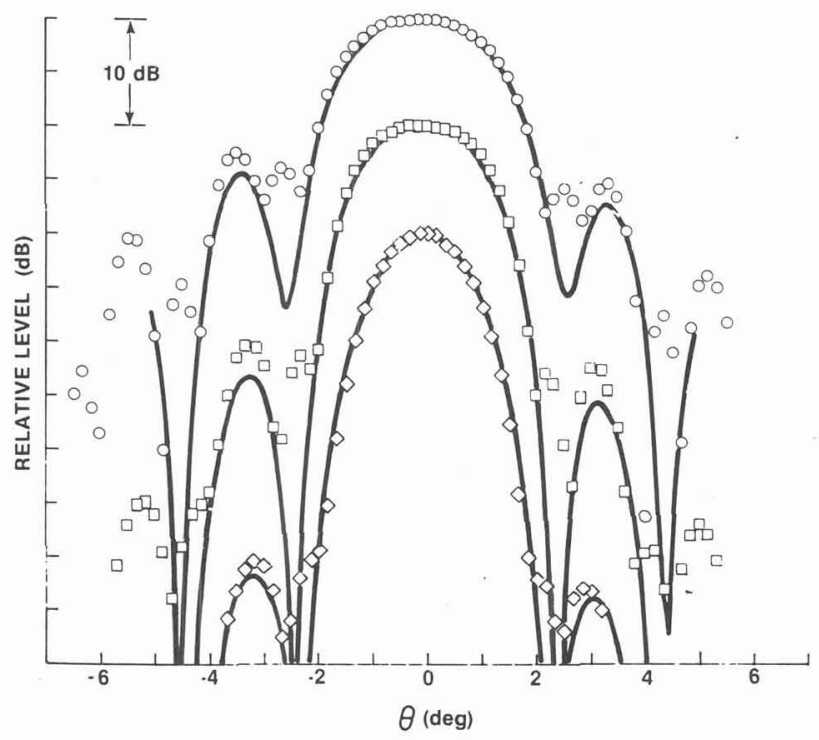

Figure 4 : Second harmonic beam patterns at $r=$ $52.2 \mathrm{~m}$ for projector voltages of $750 \mathrm{Vpp}$ (circles), $250 \mathrm{Vpp}$ (squares) and $80 \mathrm{Vpp}$ (diamonds). Solid curves : squared fundamental patterns for same voltajes.

5. Acknowledgements.- Assistance with the experiment was provided by R.E. Handfield, R.C. Leber,

W.B. McDonough, W.G. Adams, W.L. Clay and

J.P. Wilczynski. Helpful discussions with

R.H. Mellen, W.L. Konrad, Prof. A.0. Williams, Jr., P.H. Rogers and J.C. Lockwood are gratefully acknow ledged. The support and encouragement of A. Jilling are greatly appreciated. The project was sponsored by the Naval Sea Systems Command.

\section{References}

11/ Fubini-Ghiron, E., "Anomalies in the Propagation of Waves of Great Amplitude", Alta Frequenza 4. (1935) 530-581.

12/ Keck, W. and Beyer, R.T., "Frequency Spectrum of Finite Amplitude Uitrasonic Waves in Liquids", Phys. Fluids 3 (1960) 346-352.

13/ Fay, R.D., "Plane Sound Waves of Finite Amplitude", J.Acoust.Soc. Am. 3 (1931) 222-241.
14/ Blackstock, D.T., "Thermoviscous Attenuation of Plane, Periodic, Finite-Amplitude Sound Waves", J.Acoust.Soc.Am. 36 (1964) 534-542.

/5/ Naugol'nykh, K.A., Soluyan, S.I. and Khokhlov, R.V., "Spherical Waves of Finite Amplitude in a Viscous Heat Conducting Medium", Sov. Phys. Acoust. 9 (1963) 42-46.

16/ Safar, M.H., "The Propagation of Spherical Acoustic Waves of Finite Amplitude in Fresh and Sea Water", J. Sound Vib. 13 (1970) 1-7.

17/ Blackstock, D.T., "Connection Between the Fay and Fubini Solutions for Plane Sound Waves of Finite Amplitude", J.Acoust.Soc.Am. 39 (1966) 1019-1026.

18/ Ingenito, F., and Williams, A.O., Jr., "Calculation of Second Harmonic Generation in a Piston Beam", 49 (1971) 319-328.

19/ Rogers, P.H., "A Theoretical Study of SecondHarmonic Generation in the Acoustic Beam of a Circular Plane Piston", Ph.D.Thesis, Brown Univ. (1970).

/10/ Lockwood, J.C., Muir, T.G. and Blackstock,D.T., "Directive Harmonic Generation in the Radiation Field of a Circular Piston", J. Acoust. Soc. Am. 53 (1973) 1148-1153.

111/ Ostrovskii, L.A. and Fridman, V.E., "Directionality of High-Intensity Acoustic Radiation", Sov.Phys.Acoust. 18 (1973) 478-481.

112/ Fenion, F.H., "Finite-Amplitude Radiation Fields of a Plane-Piston Projector", J. Acoust. Soc. Am. 60 (1976) S98(A). See also Fenlon, F.H. and Kesner, J.W., "Noni inear Scaling Laws for Parametric Receiving Arrays", Final Report, Contract N00039-75-C-0259, ARPA Order 2910, Program Code $5 G 10$ (Westinghouse Electric Corp, Oceanic Div., P.0.Box 1488, Annapolis, MD 21404).

113/ Romanenko, E.V., "Experimental Investigation of Finite-Amplitude Spherical Waves", Sov. Phys. Acoust. 5 (1959) 100-104.

114/ See, for example, Hargrove, L.E. and Hiedemann, E.A., "Diffraction of Wide and Narrow Light Beams by Distorted Finite-Amplitude Progressive U1trasonic Waves in Water", J. Acoust. Soc. Am. 33 (1961) 1747-1749.

/15/ Krasilnikov, V.A., Shklovskaya-Kordi, V.V. and Zarembo, L.K., "On the Propagation of UTtrasonic Waves of Finite-Amplitude in Liquids", J. Acoust. Soc. Am. 29 (1957) 642-647.

116/ Ryan, R.P., Lutsch, A.G. and Beyer, R.T., "Measurement of the Distortion of Finite Uitrasonic Waves in Liquids by a Pulse Method", J. Acoust. Soc. Am. 34 (1962) 31-35.

/17/ Ryan, R.P., Attanasio, C.R. and Beyer, R.T., "Propagation of Finite-Amplitude U1trasound in a Relaxing Liquid", J. Acoust. Soc. Am. 37 (1965) 602-607.

118/ Gould, R.K., Smith, C.W., Williams, A.0., Jr., and Ryan, R.P., "Measured Structure of Harmonics Self-Generated in an Acoustic Beam", J. Acoust.Soc.Am. 40 (1966) 421-427.

119/ Browning, D.G. and Mellen, R.H., "Finite-Amplitude Distortion of $150 \mathrm{kHz}$ Acoustic Waves in Water", J.Acoust.Soc.Am. 44 (1968) 644-646. 
/20/ Allen, C.H., "Finite-Amplitude Distortion in a Sphericaily Diverging Sound Wave in Air",

Ph.D. thes is (Pennsyivania State Univ., 1950).

121/ Theobald, M.A., "Experimental Study of Outdoor Propagation of Spherically Spreading Periodic Acoustic Waves of Finite Amplitude", Univ. of Texas, Appl. Res. Labs, Rept. ARL-TR-77-5 (Jan. 1977),

122/ Mellen, R.H., private communication to the author.

/23/ Lockwood, J.C., private communication to the author.

/24/ Merklinger, H.M., Mellen, R.H. and Moffett, M.B., "Finite-Amplitude Losses in Spherical Sound Waves", J. Acoust. Soc. Am. 59 (1976) 755-759. 